\title{
Gonioscopic appearance after anterior flap sclerotomy
}

\author{
S. K. BHARGAVA \\ West of England Eye Infirmary, Exeter
}

This gonioscopic study was undertaken on eyes on which anterior flap sclerotomy with basal iridencleisis had been done, and in which chronic simple (open-angle) glaucoma haষ্f. been diagnosed. An attempt has been made to correlate the gonioscopic changes witks the postoperative result and also with some pre- and postoperative observations.

\section{Material and methods}

Ioo operations of anterior flap sclerotomy with basal iridencleisis performed on patients with chronic simple glaucoma were included in this study. The patients were examined, the operation performed and the follow-up done by the same two observers over a period of $2 \frac{1}{2}$ years.

Gonioscopy was done in every case before and 6 to 9 months after the operation with the Goldmann $\overrightarrow{0}$ single mirror gonioscopy lens and the Haag-Streit 900 slit lamp. To avoid possible confusion between two opposite numerical gradings by Scheie (1957) and Becker and Shaffer (1965), the angle was graded as follows.

Narrow:

Schwalbe's line was seen and the anterior part of the trabecular meshwork was just visible

Medium narrow: Trabecular meshwork was seen but ciliary body was not visible.

Medium wide: $\quad$ Giliary body was clearly visible along with the trabecular meshwork but not the apex and the iris root.

Wide:

All the structures in the angle were visible, i.e. iris root, ciliary body and trabecula meshwork.

Anterior flap sclerotomy with basal iridencleisis was performed under local or general anaesthesia음 After a reflection of a 8 to $10 \mathrm{~mm}$. long conjunctival flap, a $5-\mathrm{mm}$. long scleral incision was madê $\mathrm{I} .5 \mathrm{~mm}$. behind and parallel to the limbus. The scleral flap was made by incision of the sides of the scleral incision up to the limbus. The basal iris was drawn up into the scleral flap with iris forceps. A tongue of iris, based on its root, was made with a von Graefe knife, and was included in the scleral trap door. The conjunctival incision was closed with interrupted 6/o catgut sutures? Homatropine I per cent. drops and Betnesol $\mathrm{N}$ ointment were instilled at the end of the operation Homatropine I per cent. drops and Predsol N drops were continued twice daily for 3 to 4 weeks postoperatively.

\section{Results and conclusions}

At postoperative gonioscopy, the angle at the site of the scleral incision was ill-defined and no cleft was seen at the scleral incision. Sampaolesi (1969) found on gonioscopy examin $\frac{0}{?}$ ation that the lips of the scleral incision were separated in the chamber angle when the intraocular pressure was regulated after iridencleisis. Sugar (1942), however, was unable to see the outflow channels in the angle and Hobbs (1954) could not see the cleft at the incision. The present study confirms the two latter observations that no cleft was seen⿳亠口冋 with the gonioscope. 
The incarcerated iris and peripheral anterior synechiae adjacent to each end of the incision were visible. The ciliary processes were seen through the defect made in the basal portion of the iris in their normal position, to some extent anterior to the suspensory ligament of the lens. Peripheral anterior synechiae were also found to a variable extent in other parts of the angle. Their extent was calculated as a percentage of the whole of the angle obscured (Fig. I).

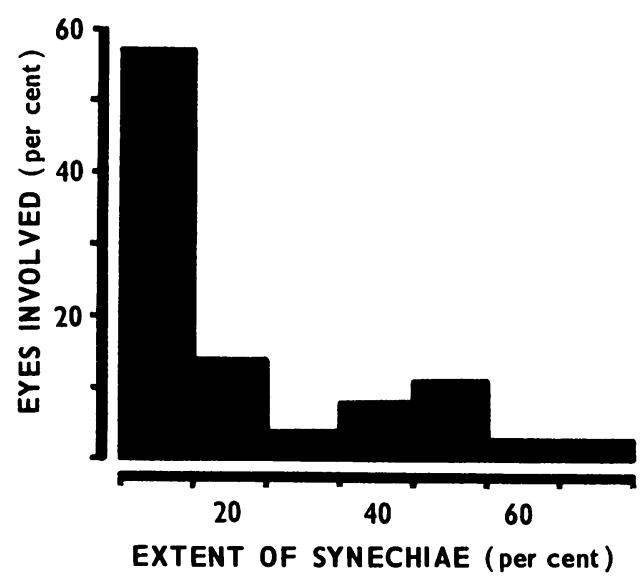

FIG. I Distribution of peripheral anterior synechiae in all eyes (100)

All the eyes had a total of approximately ro per cent. peripheral anterior synechiae at each end of the incision, and this was considered inevitable. Only 43 eyes (43 per cent.) showed additional peripheral anterior synechiae. The extent of peripheral anterior synechiae in different grades of the angle is shown in Table I.

Table I Distribution of peripheral anterior synechiae in different grades of angle

\begin{tabular}{|c|c|c|c|c|c|c|c|c|}
\hline Angle grade & No. & of & ases & & & & & $\begin{array}{c}\text { Total } \\
\text { cases }\end{array}$ \\
\hline Narrow & & 2 & & $\mathbf{I}$ & 4 & & 3 & 10 \\
\hline Medium-narrow & $\mathbf{I}$ & 6 & 3 & 5 & 7 & 3 & & 25 \\
\hline Medium-wide & $4^{2}$ & 6 & & $\mathbf{I}$ & & & & 49 \\
\hline Wide & 14 & & $\mathbf{I}$ & I & & & & I6 \\
\hline $\begin{array}{l}\text { Peripheral } \\
\text { anterior synechiae } \\
\text { (per cent.) }\end{array}$ & 10 & 20 & 30 & 40 & 50 & $6 o$ & 70 & 100 \\
\hline
\end{tabular}

To apply the $\chi^{2}$ test, the results in Table I are pooled as shown in Table II.

There is a significant relation between the decreasing preoperative width of the angle of the anterior chamber and the increasing extent of postoperative peripheral anterior synechiae formation ( $\chi^{2}$ with d.f. $\left.2=68 \cdot 8 \mathrm{I} ; \mathrm{P}<0 \cdot 00 \mathrm{I}\right)$.

Only ten eyes (Io per cent.) in this series had shallow or absent anterior chambers for a period of I to Io days postoperatively, but in all cases the anterior chambers re-formed without any surgical intervention. Seven out of these ten eyes had narrow or medium- 
Table II Pooling of results shown in Table I

\begin{tabular}{|c|c|c|c|c|}
\hline \multirow{2}{*}{$\begin{array}{l}\text { Angle } \\
\text { grade }\end{array}$} & \multicolumn{3}{|c|}{$\begin{array}{l}\text { Peripheral anterior synechiae } \\
\text { (per cent.) }\end{array}$} & \multirow{2}{*}{$\begin{array}{l}\text { Total } \\
\text { cases }\end{array}$} \\
\hline & 10 & $20-30$ & $40-70$ & \\
\hline $\begin{array}{l}\text { Narrow and } \\
\text { medium-narrow }\end{array}$ & $\mathbf{I}$ & I I & 23 & 35 \\
\hline $\begin{array}{l}\text { Medium-wide } \\
\text { and wide }\end{array}$ & $5^{6}$ & 7 & 2 & 65 \\
\hline Total & 57 & 18 & 25 & 100 \\
\hline
\end{tabular}

narrow preoperative angles and these lost the anterior chamber for more than 6 days, whereas the other three eyes were of wide-angle grade and these lost the anterior chamber. for less than 6 days. It is significant on a $\chi^{2}$ test that eyes with narrow angles lost the anterior chamber postoperatively for a longer period than eyes with wide angles $\left(\chi^{2}\right.$ with $_{\mathrm{O}}^{\circ}$ d.f. $\mathrm{I}=\mathrm{I} 0 \cdot 0 ; \mathrm{P}<0 \cdot 0 \mathrm{I})$.

The extent of peripheral anterior synechiae in cases of narrow and medium-narrow $\subseteq$ angles (these grades showing the most peripheral anterior synechiae) which retained the anterior chamber postoperatively were compared with the cases of the same grade which $\overrightarrow{0}$ lost the anterior chamber postoperatively (Fig. 2).

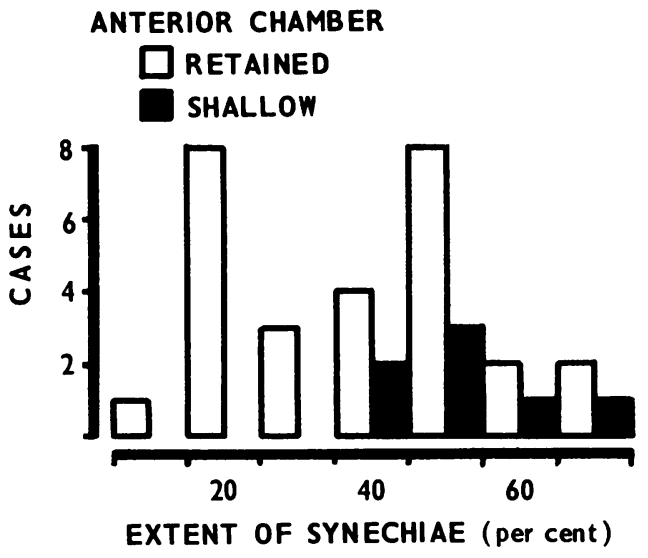

FIG. 2 Histograms of eves in the narrow and $\overline{3}$ medium-narrow angle group, comparing the extent of? peripheral anterior synechiae in eyes which post-․․ operatively retained the anterior chamber, with the extent of peripheral anterior synechiae in those which. had shallow anterior chambers

Postoperatively, 28 out of 35 eyes in these two grades retained their anterior chambers, and seven had shallow anterior chambers. In the 28 eyes which retained the anterior chamber postoperatively, twelve had peripheral anterior synechiae less than 40 per cent. and the remaining sixteen more than 40 per cent., but all of the seven eyes which had shallow anterior chambers postoperatively had over 40 per cent. of peripheral anterior synechiae.

There are significantly more peripheral anterior synechiae in the eyes which had shallow anterior chambers postoperatively than in those which retained the anterior chamber $\left(\chi^{2}\right.$ with d.f. $\left.\mathrm{I}=4.56 ; \mathrm{P}<0 \cdot 05\right)$.

In addition to formation of peripheral anterior synechiae, posterior synechiae were also estimated in each case. No mydriatic was used and posterior synechiae were assessed on 
slit-lamp examination by switching the light off-and-on. A higher incidence might well have been found if a mydriatic had been used. Their incidence was compared in different grades of the angle (Table III).

Table III Distribution of posterior synechiae in different angle grades

\begin{tabular}{|c|c|c|c|c|}
\hline \multirow{2}{*}{$\begin{array}{l}\text { Angle } \\
\text { grade }\end{array}$} & \multicolumn{3}{|c|}{ Posterior synechiae (per cent). } & \multirow{2}{*}{$\begin{array}{l}\text { Total } \\
\text { eyes }\end{array}$} \\
\hline & $0-25$ & $25-50$ & $50+$ & \\
\hline $\begin{array}{l}\text { Narrow and } \\
\text { medium-narrow }\end{array}$ & 14 & 7 & 14 & 35 \\
\hline Medium-wide & 47 & 13 & 5 & 65 \\
\hline Total & $6 I$ & 20 & 19 & 100 \\
\hline
\end{tabular}

This also shows the increasing tendency of posterior synechiae formation with the decreasing width of the preoperative angle $\left(\chi^{2}\right.$ with d.f. $\left.2=16 \cdot 42 ; \mathrm{P}<0.001\right)$. Seven out of ten cases who had absent or shallow anterior chambers showed more than $5^{\circ}$ per cent. posterior synechiae, but only twelve out of ninety eyes which retained the anterior chamber postoperatively showed more than 50 per cent. posterior synechiae. Only two cases in the whole series developed clinically detectable choroidal detachment and in both cases the anterior chamber was flat for Io days, and posterior synechiae were over 75 per cent. in extent. Thus the flat or shallow anterior chamber also significantly increases posterior synechiae formation ( $\chi^{2}$ with $\left.d . f . \mathrm{I}=\mathrm{I} 8.76 ; \mathrm{P}<0.00 \mathrm{I}\right)$.

\section{Discussion}

It has been known and well considered by various authors that peripheral anterior synechiae form after operations for glaucoma such as peripheral iridectomy, fistulizing operationsiridencleisis, trephine, and Scheie's procedure. Slow re-formation of the anterior chamber is usually suggested as an important factor (Chandler and Grant, I965; Becker and Shaffer, 1965; Duke-Elder, I949; Gorin and Posner, 1967; Hobbs, I954; Stallard, I965; Sugar, I941).

Allen (rg66) studied 34 eyes with flat or shallow anterior chambers after filtering operation for open-angle glaucoma, and in thirty eyes (88 per cent.) he found no peripheral anterior synechiae. Sollom (1969) examined 54 cases of Scheie's operation and found peripheral anterior synechiae in 47 patients ( 87 per cent.), although only half of the cases had lost the anterior chamber. He also found that the extent of peripheral anterior synechiae was related to the preoperative width of the angle and a similar relationship was seen in iridencleisis.

The present study of anterior flap sclerotomy with basal iridencleisis confirms the relationship found by Sollom (1969). The peripheral anterior synechiae are related to, and form in approximate proportion to, the preoperative width of the angle, i.e. the narrower the angle the more extensive are the peripheral anterior synechiae.

The narrow angle is not only predisposed to postoperative peripheral anterior synechiae but also to increased formation of posterior synechiae and to increased incidence of shallow or absent anterior chamber postoperatively. A shallow anterior chamber in turn further increases the formation of both peripheral anterior and posterior synechiae. It appears 
that mechanical factors, such as irido-trabecular or irido-corneal contact in anatomically narrow angles, are responsible for more peripheral anterior synechiae against a common background of postoperative traumatic anterior uveitis. These factors are further enhanced if the anterior chamber is shallow postoperatively and thus contribute to more peripheral anterior synechiae.

A factor in the formation and maintenance of a drainage bleb postoperatively in many eyes may be the blockage by peripheral anterior synechiae of some trabecular meshwork which further reduces the already impaired outflow. On the other hand, there would be less need for vigorous drainage through a bleb if peripheral anterior synechiae were eliminated.

On the period for which the shallow anterior chamber is allowed to continue before re-forming it by operation, opinions vary among different authors. Ghandler and Grant (1965) recommend 5 days, Becker and Shaffer (1965) 7 days, Stallard (1965) also 7 days, and Scheie (1964) I4 days. Allen (1966) does not consider surgical intervention to be necessary. Our study shows that there is an increased incidence of peripheral anterior synechiae when the anterior chamber remains shallow postoperatively, and it is suggested that the anterior chamber should be re-formed if it stays shallow for more than 5 to 6 days, in order to reduce the danger of peripheral anterior and posterior synechiae.

\section{Summary}

Formation of peripheral anterior synechiae after anterior flap sclerotomy with basal iridencleisis is closely related to the preoperative width of the angle of the anterior chamberthe narrower the angle the more extensive are the peripheral anterior synechiae. A similar relationship has been found between the angle width and post operative posterior synechiae. Narrow angles are further predisposed to shallow anterior chambers postoperatively and consequently to more peripheral anterior and posterior synechiae.

I wish to thank Mr. F. J. Rutter for permitting me to carry out this study on his patients, Mr. W. J. Rich for his help and advice, and Prof. C. I. Phillips for his helpful criticism.

\section{References}

Allen, J. c. (1966) Amer. F. Ophthal., 62, 509

BECKER, B., and SHAFFER, R. N. (1965) "Diagnosis and Therapy of the Glaucomas", 2nd ed., pp. 42, I 71-172. Mosby, St. Louis

CHANDler, P. A., and Grant, w. M. (1965) "Lectures on Glaucoma", pp. 96-98. Lea and Febiger, Philadelphia

DUKe-ELDER, s. (1949) Arch. Ophthal. (Chicago), 42, 538

GORIN, G., and POSNER, A. (1967) "Slit-lamp Gonioscopy", 3rd ed., pp. 86, 164, i66. Williams and Wilkins, Baltimore

HOBBS, H. E. (1954) Trans. ophthal. Soc. U.K., 74, I 53

SampaOlesi, R. (1969) Klin. Mbl. Augenheilk., 155, 6 I 5

SCHEIE, H. G. (1957) A.M.A. Arch. Ophthal., 58, $5^{10}$

(1964) Trans. ophthal. Soc. U.K., 84, 127

sollom, A. w. (1969) Brit. F. Ophthal., 53, 56 I

STALlaRd, H. B. (1965) "Eye Surgery", 4th ed., pp. 635, 694. Wright, Bristol

SUGAR, H. S. (194I) Arch. Ophthal. (Chicago), 25, 674

$$
\text { (1942) Amer. 7. Ophthal., 25, } 663
$$

